\title{
Experimental Study of Copper Nano-fluid on Thermosyphons Thermal Performance
}

\author{
Jirapol Klinbun $^{1, a, *}$ and Pradit Terdtoon ${ }^{2}$ \\ 1 Department of Mechanical Engineering, Faculty of Engineering, Rajamangala University of Technology \\ Rattanakosin, 96 Moo 3, Phutthamonthon Sai 5 Rd., Salaya, Phutthamonthon, Nakorn Prathom 73170, \\ Thailand \\ 2 Department of Mechanical Engineering, Faculty of Engineering, Chiang Mai University, 239 Huay Kaew \\ Rd., Muang District, Chiang Mai 50200, Thailand \\ E-mail: ajirapol.kli@rmutr.ac.th (Corresponding author), bpradit@eng.cmu.ac.th
}

\begin{abstract}
A new way to remove the intense heat by developing and implementing an innovative low cost compact loop thermosyphon has been widely observed. Especially, it was concluded that nano-fluids are potential heat transfer fluids to be used as working fluid in thermosyphon. Therefore, the thermophysical or transport properties of nanofluids in thermosyphon need to be discussed. In present work was to experimental study the thermal performance of thermosyphon using a copper nano-fluid as a working fluid. The experiment was performed in order to measure the temperature distribution and compare heat transfer rate of the thermosymphon with nano-fluid and with pure water. The concentration of copper nano-particle was 10,30 and $50 \mathrm{ppm}$. The tested working temperature was 60,70 and $80^{\circ} \mathrm{C}$. Results shown that the concentration of $50 \mathrm{ppm}$ of copper nano-fluid improved thermal performance compared with the case of pure water. The optimum and behavior of copper nano-fluid in thermosyphon is presented, which highlights all of the beforehand mentioned advantages.
\end{abstract}

Keywords: Nano-fluid, thermosyphon, thermal performance, thermal resistance.

ENGINEERING JOURNAL Volume 21 Issue 1

Received 23 February 2016

Accepted 19 August 2016

Published 31 January 2017

Online at http://www.engj.org/

DOI:10.4186/ej.2017.21.1.255 


\section{Introduction}

Heat removal is one of the important challenges in designing electronic component. Recently, heat pipes are used to remove intense heat from small electronic components in desktop and laptop computers. Heat pipe is a heat transfer device which transports large quantities of heat with minimum temperature gradient without any additional power between the two temperature limits [8]. A heat pipe consists of essentially three parts: an evaporator, an adiabatic section, and a condenser. These three parts are significantly effect on performance of a heat pipe. The heat input is supplied to the evaporator section of the heat pipe; the working fluid is heated until it vaporizes. The latent heat of evaporation is transported to condenser section in vapor form with a very small temperature difference. The latent heat of evaporation is transported to condenser section in vapor form with a very small temperature difference. The vapor releases heat to sink and condenses become to liquid. The gravity forces existing on the liquid film back to the evaporator. The difference functions between the evaporator and condenser sections of a heat pipe, but that have common liquid and vapor streams.

Recently, the usual enhancement techniques for heat transfer can barely meet the ever increasing demand of heat removal in high energy devices. Normally, fluids have poor heat transfer properties compared to most solids and it becomes a primary obstacle to applied in case of the heat exchangers at high effectiveness. The initiative idea to developed and seek the solid particles having thermal conductivities several are higher than those of conventional fluids. For example, the thermal conductivity of copper at the room temperature is $=700$ times greater than that of water and $=3000$ times greater than that of engine oil. Thus, the thermal conductivity of metallic liquid is much greater than that the non-metallic liquids. Many researchers try to suspend ultrafine solid particles in the fluid for improving the heat transfer properties of a fluid. They use particles in the scale of millimeters or even micrometers, such as metallic, non-metallic and polymeric, can be mixed into fluids. However, they often suffer from instability and rheological problems. In particular, the particles tend to settle rapidly. Hence, even though the slurries give better thermal properties they are unable to act as coolants in practical applications. There is an urgent need for new and innovative coolants with improved performance. The novel heat transfer fluids containing suspensions of nano-particles has been proposed is called "Nano-fluids", which are engineered by suspending experimental investigations have revealed that nano-fluids have remarkably higher thermal conductivity and greater heat transfer characteristics than conventional pure fluids [1-8]. In convective heat transfer in nano-fluids, the heat transfer coefficient depends not only on the thermal conductivity but also on other properties, such as the specific heat, density, and dynamic viscosity of a nano-fluid. At low volume fractions, the density and specific heat of nano-fluids looks to be very similar to those characterizing the base fluid. Kang et al. [9] discussed about the thermal enhancement of heat pipe performance using silver nano-fluid as the working fluid. The higher thermal performance of nano-fluids indicates nano-fluid potential as a substitute for conventional pure water in grooved heat pipes. This finding survey makes nano-fluid much more attractive as a cooling fluid for devices with high energy density. The significant improvement of thermal conductivity [10-13], convective heat transfer [14-16] and boiling heat transfer [17-21] using nano-fluids were investigated. The experimental results showed that the thermal resistance of heat pipe with nano-fluids was lower than that of pipes containing pure water.

Copper nano-particles are an interesting type of material having multifunctional properties with various applications in the fields of catalysts, batteries, magnetic storage media, solar energy, and superconductors. There are several methods available to synthesis copper nano-particles with various morphologies. In addition, copper nano-particles have grate advantages over conventional materials because of their surface area. These nano-particles are to agglomerate with time and tend to lower the surface energy. The copper is dispersed very high reaction rates which is used for hydro cracking, coal liquefaction, etc. Finally, copper nano-particles are also used in nano-fluid where dispersed nano-particles are used for increasing the thermal conductivity of fluid.

The objective of this work is to study about the thermal performance of heat pipe using copper nanofluid compared with the DI water. In this analysis, heat pipe of copper container. The DI water and copper are used as working fluids separately in the heat pipe. The experiments are conducted for various working temperature of heat pipe. 


\section{Experimental Analysis}

\subsection{Description of Experiment Setup}

The nano-particles used in these work were copper $(\mathrm{Cu})$ with $40 \mathrm{~nm}$ in size. The tested concentrations were 10, 30, and $50 \mathrm{ppm}$. Cu-nano-fluid was prepared using two-steps. $\mathrm{Cu}$ nano-particles were prepared first. The $\mathrm{Cu}$-nano-particles were then added to pure water. No surfactant was used in the $\mathrm{Cu}$-nano-fluid suspensions. The mixture was prepared using an ultrasonic homogenizer.

A schematic layout of the experiment apparatus was shown in Fig. 1. Thermosyphon made from copper tube. It was $25.4 \mathrm{~mm}$ of outside diameter and $600 \mathrm{~mm}$ in length. The thermosyphon was divided into three sections; the evaporator, adiabatic and condenser section. There are equal lengths of $200 \mathrm{~mm}$. Heat was supplied to the evaporator by circumferential electric heater. The working temperature was 60,70 , and $80^{\circ} \mathrm{C}$. Pure water or nano-fluid was used as working fluid, and was filled with $50 \%$ of volume evaporator. A water bath was used to circulate the cooling water (always maintained at $30^{\circ} \mathrm{C}$ ) to the condenser. Fourteen K-type thermocouples that were connected to digital temperature recorder (Yokokawa MW 2000) were used to measure the temperature at the axial position on the thermosyphon tube. Since ability of thermosyphon, the cooling water was circulated through the condenser jacket before the heat was supplied to the evaporator. In addition, the inlet and outlet temperatures of the cooling water were measured using two thermocouples. The adiabatic section of the heat pipe was completely insulated with the rock wool. The amount of heat loss from the evaporator and condenser surface was negligible.

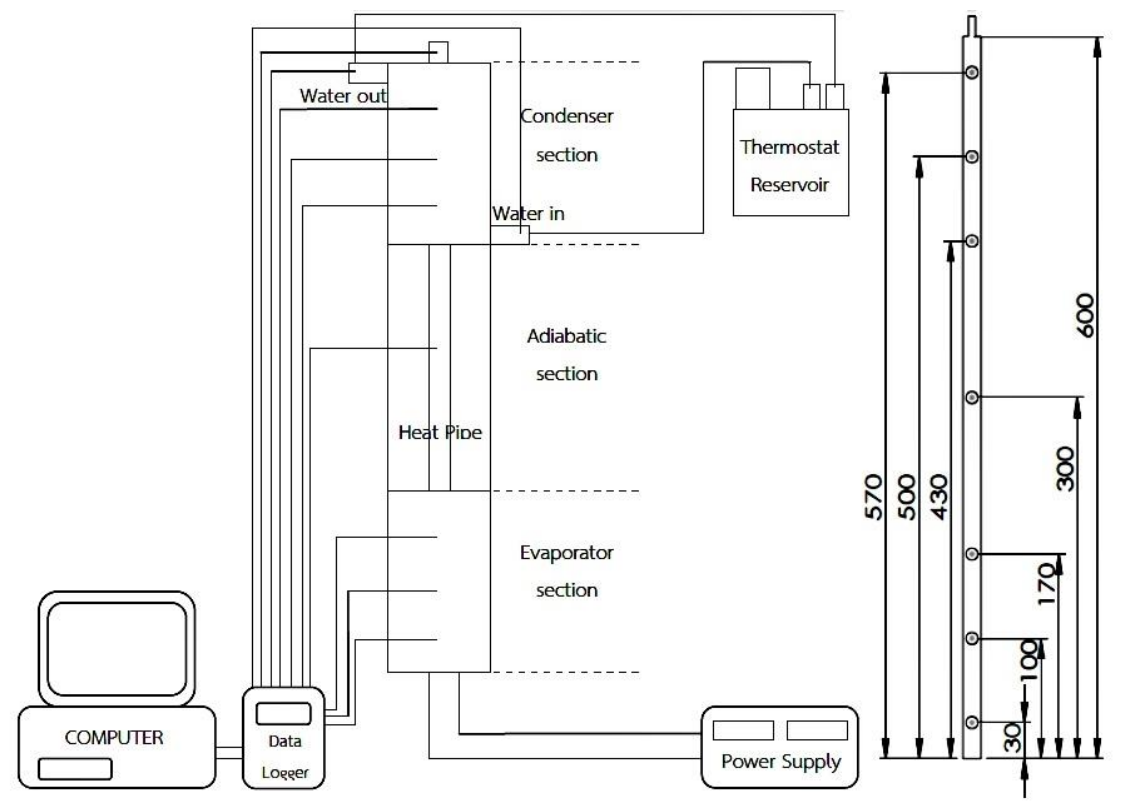

Fig. 1. Schematic of the experimental setup.

Table 1. Accuracy and uncertainty of measurements.

\begin{tabular}{lcc}
\hline Instruments & Accuracy & Uncertainty \\
\hline Thermocouple type K, & $0.1 \%$ & \pm 0.1 \\
Data logger $\left({ }^{\circ} \mathrm{C}\right)$ & & \\
Digital power meter & $0.1 \%$ & $\pm 0.1-1.0$ \\
Digital weight scales & $0.01 \%$ & $0.01-1.0$ \\
$(1000 \mathrm{~g})$ & & \\
\hline
\end{tabular}




\subsection{Experimental Procedure}

In this work, the effect of nano-fluid concentration and working temperature were examined. The experiment runs were carried out according to the following steps:

1. The thermosyphon was set up. One of these was filled with pure water and another with copper nano-fluid. The inclination of pipe was controlled at $90^{\circ}$.

2. The power input was supplied to the thermosyphon until the desired working temperature level.

3. At the steady state after a time period of about $15 \mathrm{~min}$, the surface temperatures were measured and recorded.

4. After finishing the above steps, cooling water was allowed to flow through the condenser to cool the thermosyphon and to make it ready for further experimental purpose.

5. The thermosyphon was charged with another concentration of working fluid. The tested concentration was changed using the following values: 10,30 , and $50 \mathrm{ppm}$ respectively. Then repeated step 1-4 again.

\subsection{Calculation Procedure}

The obtain measurement data of temperature were used to calculate the heat rate and the total thermal resistance.

The output heat transfer rate from the condenser was computed by applying an energy balance to the condenser flow. Thus, the heat transfer rate of heat pipe was calculated using the equation.

$$
\dot{Q}=\dot{m} C_{p}\left(T_{c o}-T_{c i}\right)
$$

And the thermal resistance $(\mathrm{R})$ was defined as

$$
R=\frac{\left(T_{e}-T_{c}\right)}{\dot{Q}}
$$

where $T_{e}, T_{c}$ were averaged values of temperatures at the evaporator and condenser sections respectively and $\dot{Q}$ is the heat supplied to the system.

\section{Results and Discussion}

For this section, experimental results included the study of heat transfer in thermosyphon and thermal resistances were introduced. Using wall temperature reading, the total resistance of the tested thermosyphon was calculated for different values of operating parameters. The results were carried out varying the working temperature $\left(60,70,80^{\circ} \mathrm{C}\right)$. Pure water and nano-fluid used as working fluid were charged with $50 \%$ of volume evaporator. The inclination angle of pipe was fixed at $90^{\circ}$. Nano-particles concentration were varied as 10,30,50 ppm. Thermal performance of thermosyphon using pure water and nano-fluid as a working fluid

Figure 2 showed the wall temperature distribution along axial position of thermosyphon for different working temperature $\left(60,70,80^{\circ} \mathrm{C}\right)$. From Fig. $2(\mathrm{a})$, the wall temperature distributions of the thermosyphon with pure water at working temperature $80^{\circ} \mathrm{C}$ were $86.4^{\circ} \mathrm{C}, 85.2^{\circ} \mathrm{C}$ and $84.5^{\circ} \mathrm{C}$ of evaporator section, $80.2^{\circ} \mathrm{C}$ of adiabatic section, $66.1^{\circ} \mathrm{C}, 59.4^{\circ} \mathrm{C}$ and $56.1^{\circ} \mathrm{C}$ of condenser section, respectively. 


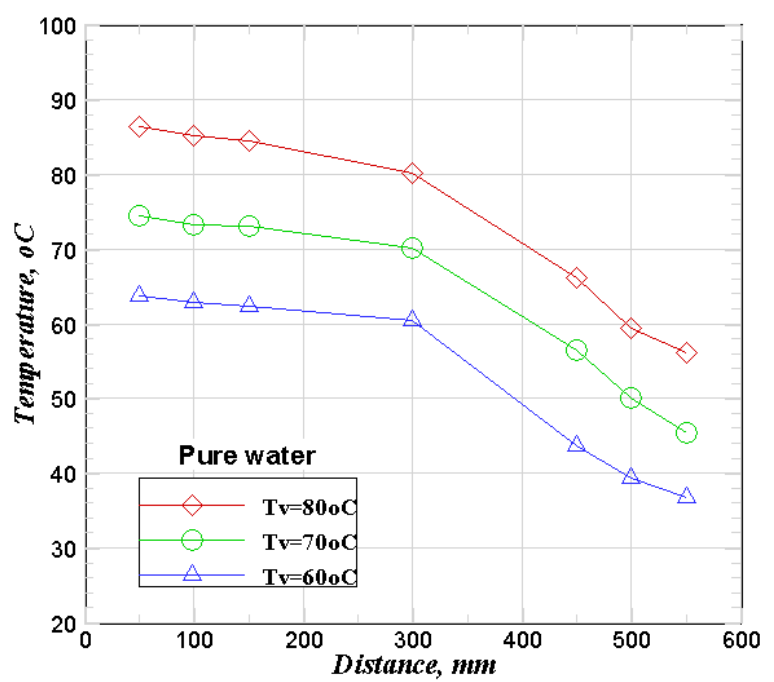

Fig. 2(a). Temperature distribution along the thermosyphon surface using pure water as working fluid for different working temperature.

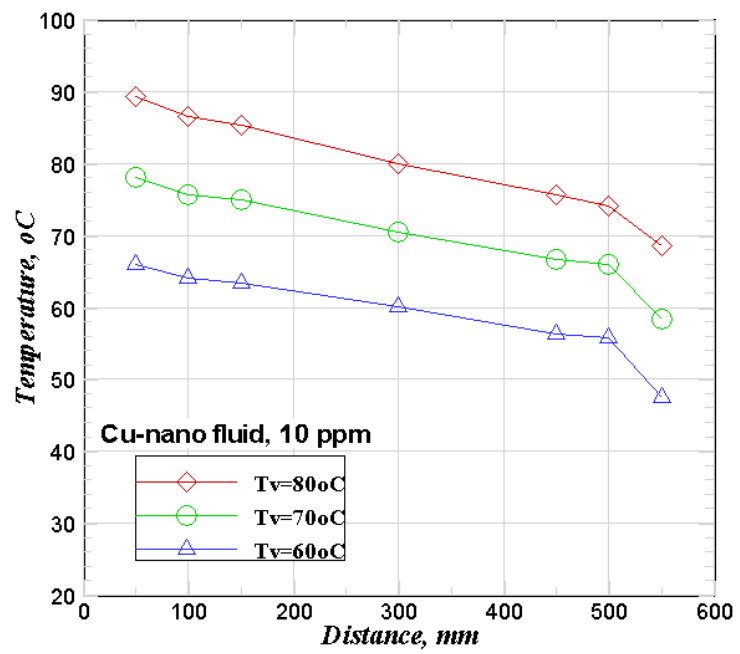

Fig. 2(b). Temperature distribution along the thermosyphon surface using 10 ppm Cu-nano fluid as working fluid for different working temperature.

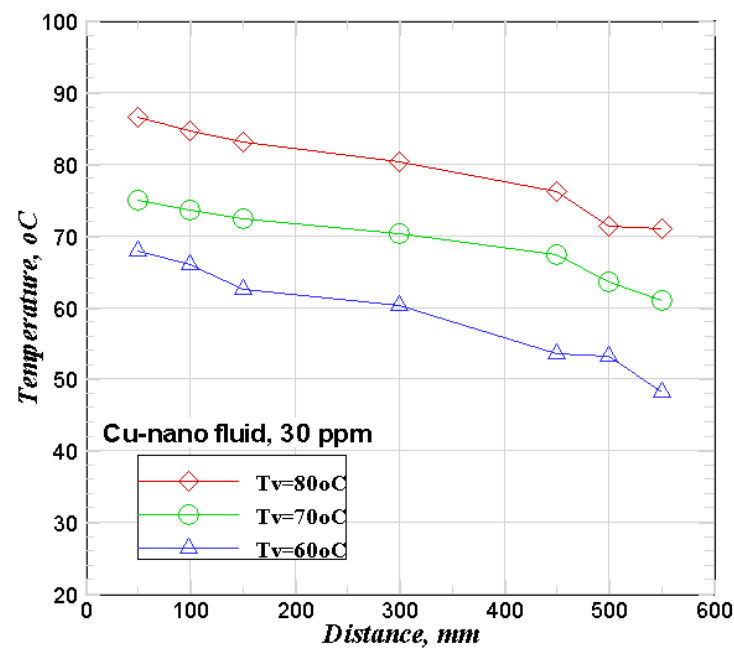

Fig. 2(c). Temperature distribution along the thermosyphon surface using 30 ppm Cu-nano fluid as working fluid for different working temperature. 


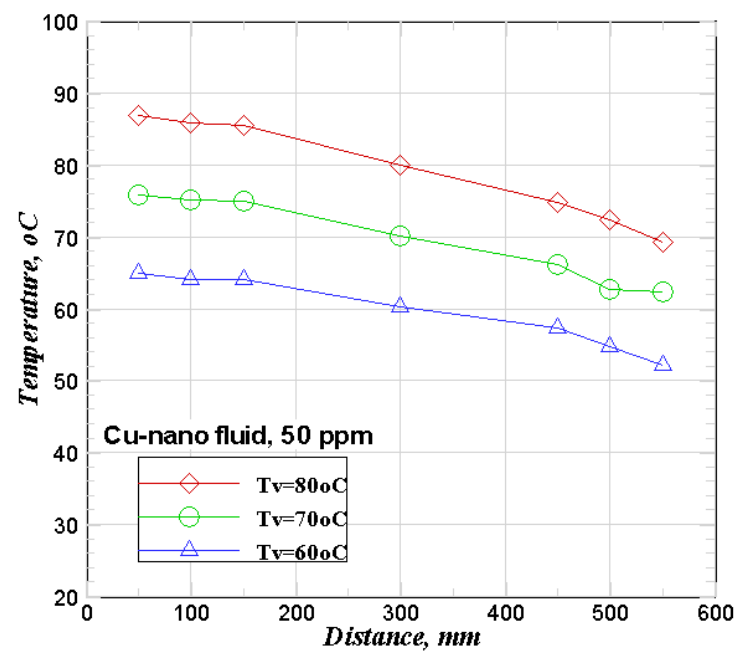

Fig. 2(d). Temperature distribution along the thermosyphon surface using $50 \mathrm{ppm} \mathrm{Cu}$-nano fluid as working fluid for different working temperature.

After adding $\mathrm{Cu}$-nano-particles in the pure water $(10 \mathrm{ppm})$ as shown in Fig. 2(b), the wall temperature at condenser section increased from $75.6^{\circ} \mathrm{C}$ to $68.5^{\circ} \mathrm{C}$. When increasing nano-particles in the working fluid, the concentration became $30 \mathrm{ppm}$ and $50 \mathrm{ppm}$ (Fig. 2(c) and Fig. 2(d)), the wall temperature at condenser section increase smaller than that thermosyphon under various working temperatures. This trend was same all working temperatures. This is because the gravity force affect to film condenses of nano-fluid falls from condenser section to evaporator section faster than water. Therefore, the film thickness of nano-fluid is thin than film condenses of water. As a result the temperature of condenser section of thermosyphon with nano-fulid is higher than with pure water.

Figure 3 illustrated the surface temperature along the thermosyphon for different concentration of nano-fluids as compared to pure water, at working temperature of $70^{\circ} \mathrm{C}$. As shown in the figure, the surface temperature increases with increasing the concentration of $\mathrm{Cu}$-nano-particles. Thermal resistance of thermosyphon using pure water and nano-fluid as a working fluid

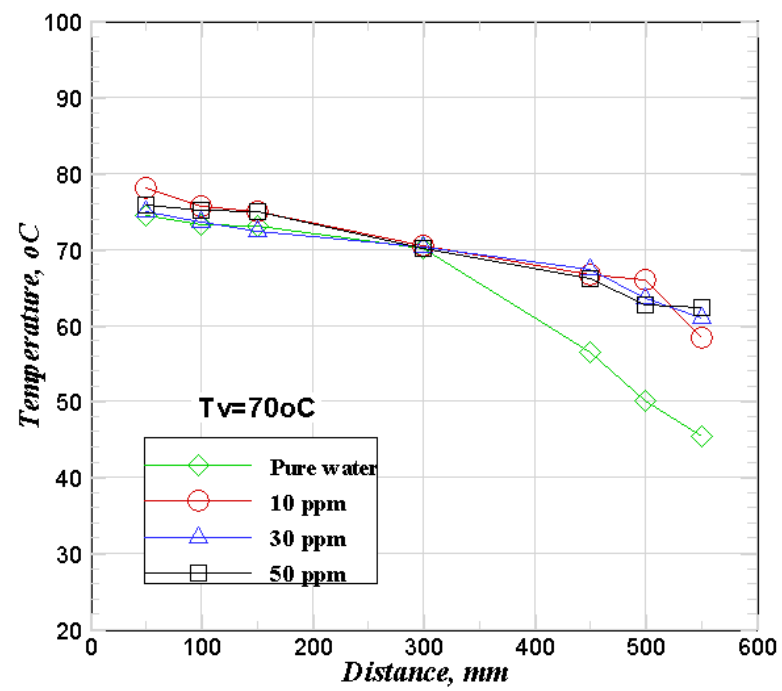

Fig. 3. Temperature distribution of the thermosyphon with different concentrations $\mathrm{Cu}$-nano-fluids as compared to pure water.

Figure 4 illustrated the variation of the total thermal resistance of the thermosyphon, with working temperature at different concentration $\mathrm{Cu}$-nano-fluids. The thermal resistance $(\mathrm{R})$ of the thermosyphon is defined as where Te and Tc are average values of temperatures at the evaporator and condenser sections respectively and Q is the heat transfer rate of the heat pipe at the condenser section. From the Fig. 4, it is clear that the thermal resistance of thermosyphon decreases for both the working fluids with increasing 
values of working temperature and the concentration. At low working temperature, the thermal resistances of both the thermosyphon are high because of the relatively solid liquid film that resides in the evaporator section. When the working temperature increases, these thermal resistances condense quickly to their minimum value. The thermal resistance of the nano-fluids is always less than the DI water. The heat transfer enhancement of a thermosyphon using nano-fluids is due to the thermo physical properties of nano-fluids, such as heat capacity $(\mathrm{Cp})$ is higher than DI water. But the other hand, the formation of thin porous coating layer produced by the nanoparticles in the surface of inner pipe region is reducing surface roughness. These results to liquid condense from condenser section return to evaporator section faster than DI water and it significantly reduces the thermal resistance of the thermosyphon using nano-fluids. Therefore, the all reason it is corresponding heat transfer as show in Fig. 5.

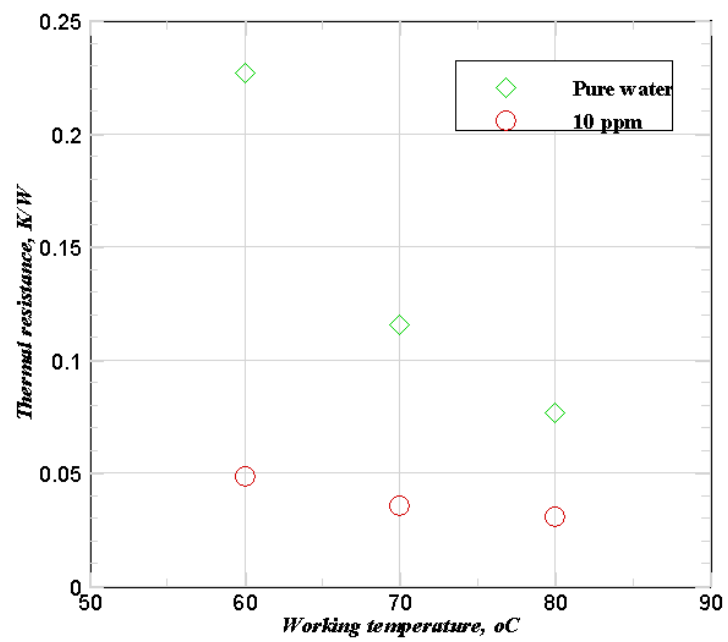

Fig. 4(a). Variation of thermal resistance with working temperature at $10 \mathrm{ppm} \mathrm{Cu}$-nano-fluids and pure water.

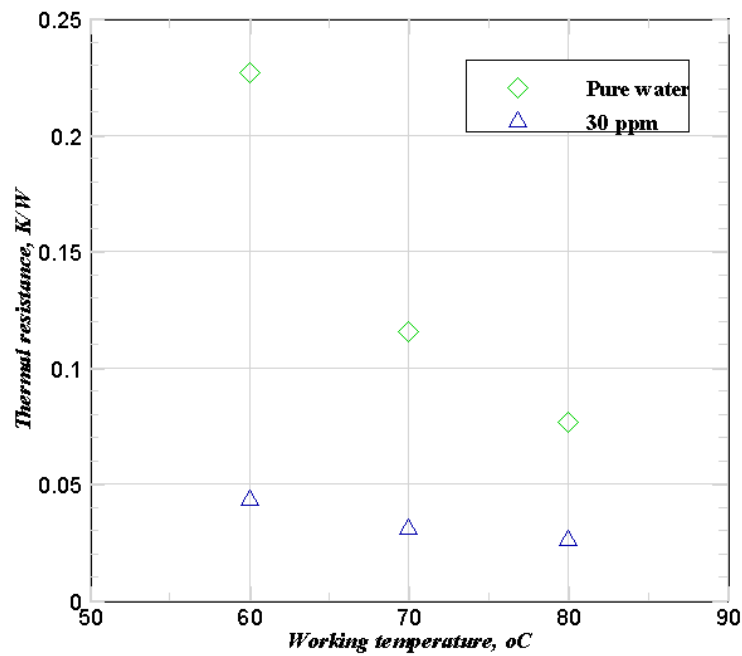

Fig. 4(b). Variation of thermal resistance with working temperature at $30 \mathrm{ppm} \mathrm{Cu}$-nano-fluids and pure water. 


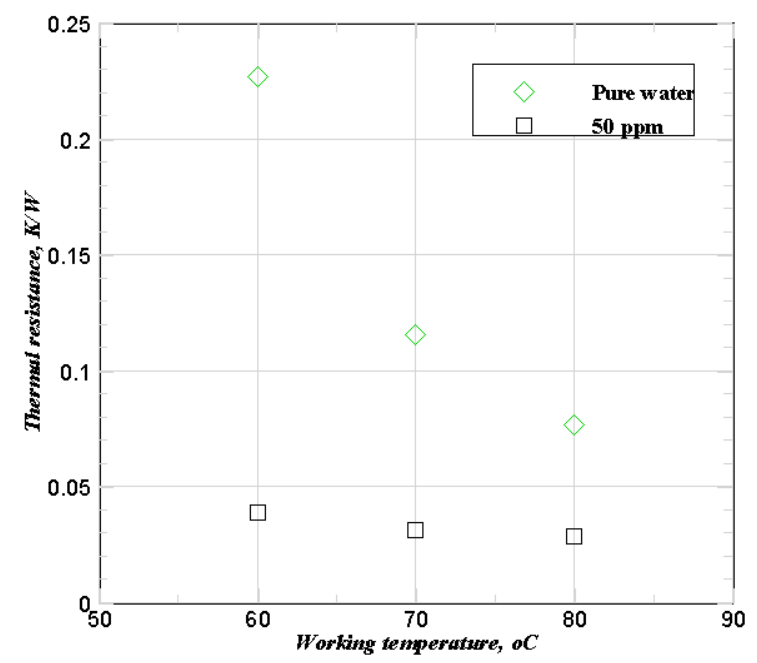

Fig. 4(c). Variation of thermal resistance with working temperature at $50 \mathrm{ppm} \mathrm{Cu}$-nano-fluids and pure water.

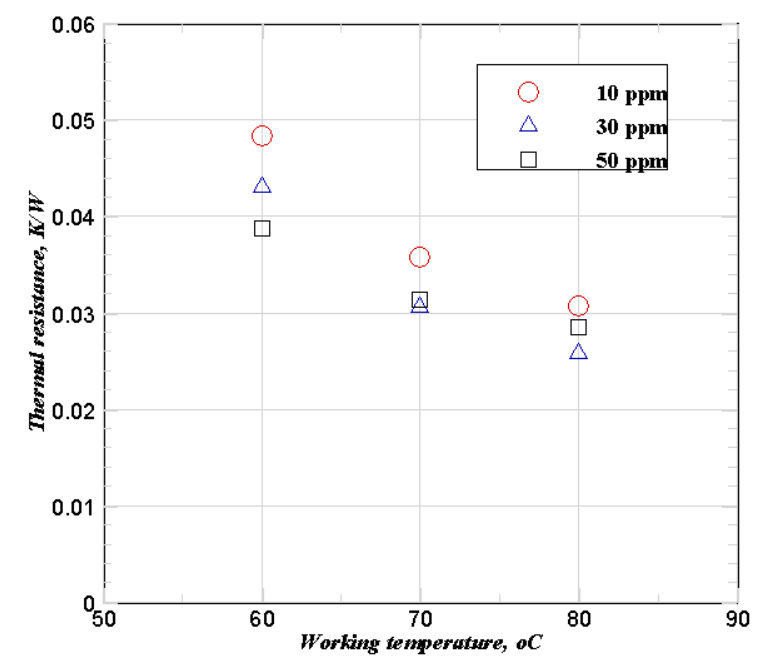

Fig. 4(d). Variation of thermal resistance with working temperature at different concentration Cu-nanofluids.

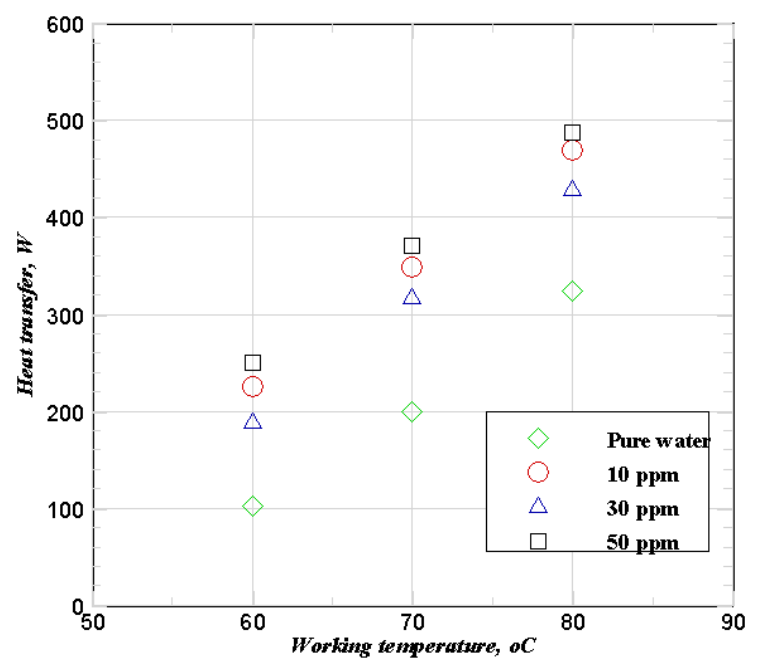

Fig. 5. Heat transfer of the thermosyphon with different concentrations $\mathrm{Cu}$-nano-fluids as compared to pure water. 


\section{Conclusions}

In this paper the thermal enhancement of the thermosyphon performance, using $\mathrm{Cu}$-nano-fluid compared with DI-water as the working fluid was experimentally tested. Conclusions may be carried out from the results of the performance tests. The more $\mathrm{Cu}$ nano-particles are dispersed in the working fluid enhancement of the thermosyphon performance expressd by of the performance line (heat transfer and thermal resistance graph). The thermal resistance of the thermosyphon with nano-particles is lower than that with DI-water. It is shown that the thermal resistance decreases with increasing concentration. Results indicate that the $\mathrm{Cu}$-nano-fluid has a great potential as working fluid for thermosyphon of higher thermal performance. In addition, nano-fluids are suitable for using in many applications than the conventional cooling mediums.

\section{Acknowledgements}

The authors thank Rajamangala University of Technology Rattanakosin and Fujikura (Thailand) Company for providing the necessary facilities in order to accomplish this piece of work.

\section{References}

[1] S. U. S. Choi and J. A. Eastman, "Enhancing thermal conductivity of fluids with nanoparticles," ASME International Mechanical Engineering Congress \& Exposition, November 12-17, 1995.

[2] S. Lee, S. U. S. Choi, S. Li, and J. A. Eastman, "Measuring thermal conductivity of fluids containing oxide nano-particles," J. Heat Transfer, vol. 121, no. 2, pp. 280-289, May, 1999.

[3] X. Wang, W. Xu, and S. U. S. Choi, "Thermal conductivity of nanoparticle-fluid mixture," Journal of Thermophysics and Heat Transfer, vol. 13, no. 4, pp. 474-480, December, 1999.

[4] H. Xie, J. Wang, T. Xi, and Y. Liu, "Thermal conductivity of suspensions containing nanosized SiC particles, International Journal of Thermophysics, vol. 23, no. 2, pp. 571-580, March, 2002.

[5] H. Xie, H. Lee, W. Youn, and M. Choi, "Nanofluids containing multiwalled carbon nanotubes and their enhanced thermal conductivities," Journal of Applied Physics, vol. 94, no. 8, pp. 4967-4971, October, 2003.

[6] H. E. Patel, S. K. Das, T. Sundararajan, A. Sreekumaran Nair, B. George, and T. Pradeep, "Thermal conductivities of naked and monolayer protected metal nanoparticles based nanofluids: Manifestation of anomalous enhancement and chemical effects," Applied Physics Letters, vol. 83, no. 14, pp. 2931-2933, October, 2003.

[7] T. Cho, I. Baek, J. Lee, and S. Park, "Preparation of nanofluids containing suspended silver particles for enhancing fluid thermal conductivity of fluids," Journal of Industrial and Engineering Chemistry, vol. 11, no. 3, pp. 400-406, March, 2005.

[8] R. Senthilkumar., S. Vaidyanathan, and B. Sivaraman, "Effect of inclination angle in heat pipe performance using copper nanofluid," J. Procedia Engineering, vol. 38, pp. 3715-3721, 2012.

[9] S. K Das, N. Putra, P. Thiesen, and W. Roetzel, "Temperature dependence of thermal conductivity enhancement for nanofluids," Journal of Heat Transfer, vol. 125, no. 4, pp. 567-574, July, 2003.

[10] S. W. Kang, W. C. Wei, S. H. Tsai, and S. Y. Yang, "Experimental investigation of silver nano-fluid on heat pipe thermal performance," Applied Thermal Engineering, vol. 26, pp. 2377-2382, April, 2006.

[11] X. Q. Wang and A. S. Mujumdar, "A review on nanofluids-Part I: Theoretical and numerical investigations," Brazilian Journal of Chemical Engineering, vol. 25, no. 4, pp. 613-630, December, 2008.

[12] H. Masuda, A. Ebata, K. Teramae, and N. Hishinuma, "Alteration of thermal conductivity and viscosity of liquid by dispersing ultra-fine particles. Dispersion of $\mathrm{Al}_{2} \mathrm{O}_{3}, \mathrm{SiO}_{2}$ and $\mathrm{TiO}_{2}$ ultra-fine particles," Asia Science and Technology Portal, vol. 7, no. 4, pp. 227-233, 1993.

[13] Y. Xuan and Q. Li, "Heat transfer enhancement of nanofluids," Int. J. Heat Fluid Flow, vol. 21, no. 1, pp. 58-64, 2000.

[14] S. A. Putnam, D. G. Cahill, and P. V. Braun, "Thermal conductivity of nanoparticle suspensions," Journal of Applied Physics, vol. 99, no. 4, pp. 084308-1-6, April, 2006.

[15] B. C. Pak and Y. I. Cho, "Hydrodynamic and heat transfer study of dispersed fluids with submicron metallic oxide particles," Experimental Heat Transfer, vol. 11, pp. 151-170, 1998. 
[16] Y. Xuan and W. Roetzel, "Conceptions for heat transfer correlation of nanofluids," Int. J. Heat Mass Transfer, vol. 43, no. 19, pp. 3701-3707, 2000.

[17] Y. Xuan and Q. Li, "Investigation on convective heat transfer and flow features of nanofluids," J. Heat Transfer, vol. 125, no. 1, pp. 151-155, February, 2003.

[18] S. K. Das, N. Putra, and W. Roetzel, "Pool boiling characteristics of nano-fluids," Int. J. Heat Mass Transfer, vol. 46, no. 5, pp. 851-862, February, 2003.

[19] S. M. Kwark, R. Kumara, G. Morenoa, J. Yoob, and S. M. Youa, "Pool boiling characteristics of low concentration nanofluids," Int. J. Heat Mass Transfer, vol. 53, no. 5-6, pp. 972-981, February, 2010.

[20] K. H. Krishna, H. Ganapathy, G. Sateesh, and S. K. Das, "Pool Boiling Characteristics of Metallic Nanofluids," Journal of Heat Transfer, vol. 133, no. 11, pp. 111501-1-8, August, 2011.

[21] M. M. Sarafraz, F. Hormozi, and S. M. Peyghambarzadeh, "Pool boiling heat transfer to aqueous alumina nano-fluids on the plain and concentric circular micro-structured (CCM) surfaces," Experimental Thermal and Fluid Science, vol. 72, pp. 125-139, April, 2016.

\section{Nomenclature}

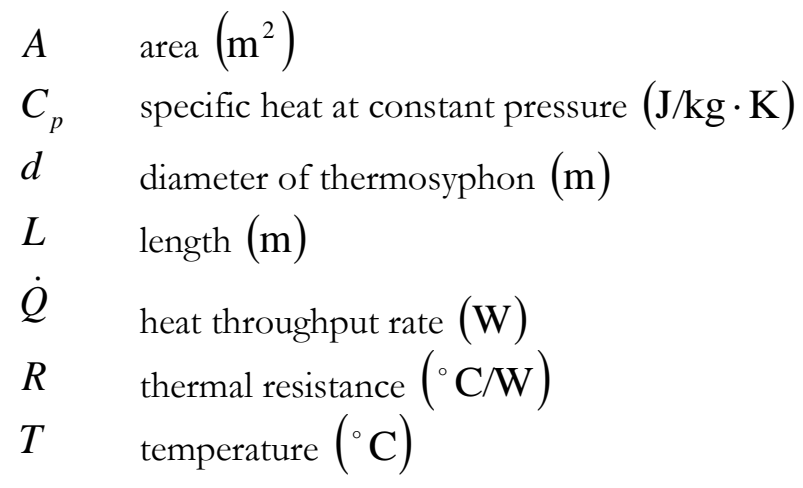

\section{Subscripts}

$c \quad$ condenser section

$e \quad$ evaporator section

$i \quad$ inlet

$o \quad$ outlet 